Qadeer Arshad, PhD*

Niccolo Cerchiai, MD*

Usman Goga, BSc

Yuliya Nigmatullina, PhD

R. Ed Roberts, PhD

Augusto P. Casani, MD

John F. Golding, PhD

Michael A. Gresty, PhD

Adolfo M. Bronstein, $\mathrm{MD}, \mathrm{PhD}$

\section{ELECTROCORTICAL THERAPY FOR MOTION SICKNESS \\ OPEN}

Given a sufficiently provocative stimulus, almost everyone can be made motion sick, with approximately one-third experiencing significant symptoms on long bus trips, on ships, or in light aircraft. ${ }^{1-4}$ Current countermeasures are either behavioral or pharmacologic. Behavioral measures include habituation/desensitization treatment protocols $s^{5}$ as well as positioning the head in alignment with the direction of the gravito-inertial force and maintaining a stable horizontal reference frame. ${ }^{5}$ Pharmacologic measures include antimuscarinics, H1 antihistamines, and sympathomimetics, which all detrimentally impact upon cognitive function, rendering them inappropriate for occupational use. ${ }^{5}$ All current therapies are only partially effective.

Since a functioning vestibular system is critical to the development of motion sickness, ${ }^{1}$ we proposed that suppressing vestibular activity could increase tolerance to nauseogenic motion stimuli. We previously showed that application of transcranial direct current stimulation (tDCS), specifically unipolar cathodal stimulation over the left parietal cortex, results in suppression of the vestibular system. ${ }^{6}$ Herein, we assessed whether such suppression of vestibular activity using tDCS in normal controls may alleviate motion sickness.

Classification of evidence. This study provides Class II evidence that in normal volunteers undergoing off-axis rotation, left parietal cortex cathodal stimulation increases the time to the development of moderate nausea.

Methods. We implemented a well-established model of inducing motion sickness termed off-vertical axis rotation (OVAR). Subjects were seated in a motorized chair (NKI; Pittsburgh, PA) with the torso restrained by a 5-point seatbelt with the head, legs, and feet additionally secured with cushioned clamps. The chair was rotated rightwards in the dark, accelerating and tilting gradually over 30 seconds to reach a constant rotational velocity of $72 \mathrm{deg} / \mathrm{s}$, frequency of $0.2 \mathrm{~Hz}$, at a tilt of 18 degrees. ${ }^{7}$ Twenty right-handed subjects (10 M; $10 \mathrm{~F}$ not within 3 days of menstruation) were randomly allocated into 2 age- and sex-matched groups
Clinical/Scientific Notes

(groups 1 and 2). It was ensured that individuals in both groups were matched for susceptibility to motion sickness as determined by adult-based motion sickness questionnaire scores (MSB scores; see the figure, B for each individual's susceptibility score). ${ }^{8}$

The experimental design was specifically chosen to test whether tDCS is potentially effective as a prophylactic or abortive treatment. Both groups underwent an initial OVAR session during sham tDCS stimulation only. The time taken to self-report (1) onset of symptoms (i.e., stomach awareness); (2) the primary outcome measure, onset of moderate nausea (i.e., total OVAR duration, with no upper time limit); and (3) subsequent self-recovery were recorded. Subjects were given a 1 -hour rest period in a separate room, after which all reported full recovery. Critically, despite recovery, at this time point previous research has shown that subjects have higher motion sickness susceptibility, ${ }^{9}$ thus allowing us to test the efficacy of tDCS during enhanced susceptibility. After recovery, unipolar tDCS was applied (1.5 mA with a ramp-up and fade-out time of 10 seconds; electrode placement area $25 \mathrm{~cm}^{2}$; for electrode placement on the scalp, we parted the hair and electrodes were held in place with an EEG cap ${ }^{6}$ ) with 2 possible different polarities in a double-blind design. ${ }^{6}$ For group 1 (cathodal) and group 2 (anodal), stimulation was applied initially for 15 minutes immediately prior to the second OVAR session over left parietal cortex and stimulation continued for either a further 15 minutes during the rotation or until subjects reported moderate nausea (i.e., whichever came first). No subjects dropped out or complained of any symptoms associated with either tDCS stimulation or tDCSmediated vestibular suppression.

Results. The figure summarizes the results of the experiment. Repeated-measures analysis of variance for cathodal tDCS stimulation with within-subjects factors measurement (OVAR duration, first onset of symptoms, and time to recovery) and condition (before tDCS, after tDCS) showed a significant measurement $\times$ condition interaction $(F=9.48$, $d f=2, p=0.033$; figure, A). Post hoc paired $t$ tests (2-tailed) with Bonferroni corrections showed that following cathodal stimulation, OVAR duration (i.e., time taken for the onset of moderate nausea) 
A

A

(2)

800<smiles>C1CCCCC1</smiles>

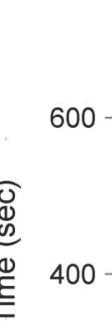

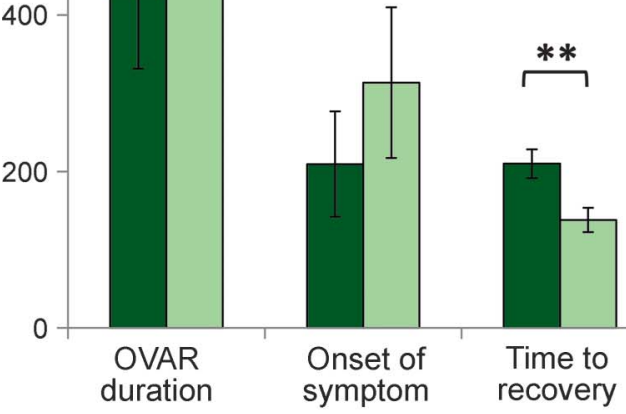

B

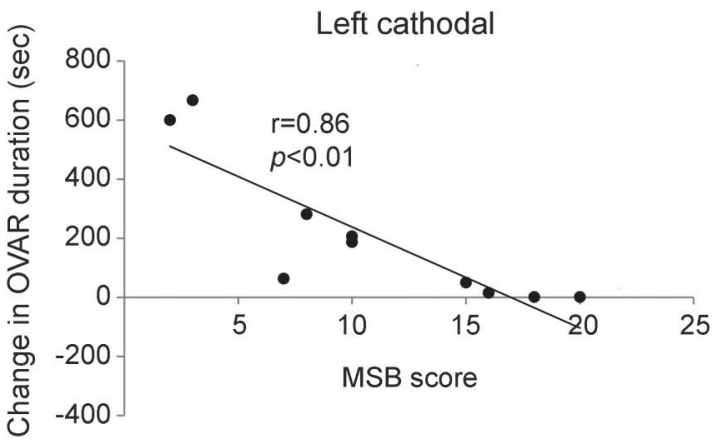

Left cathodal

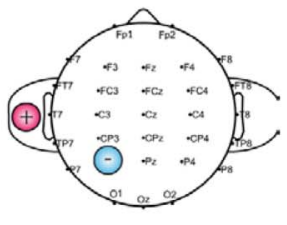

ry

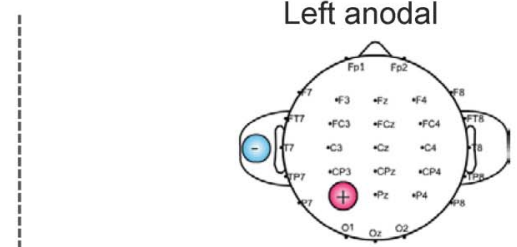

Before tDCS

After tDCS

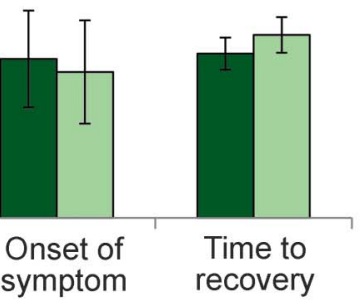

Left anodal

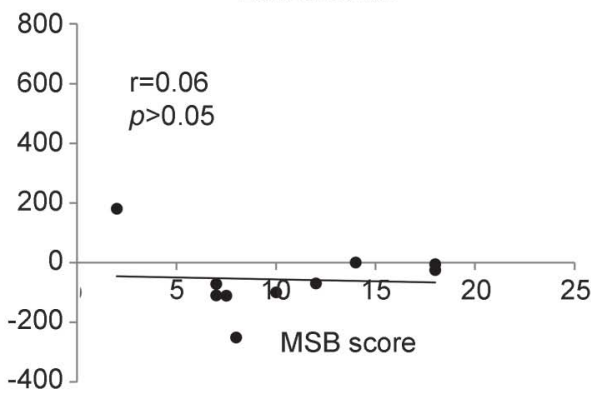

(A) (Left upper panel) Following left cathodal transcranial direct current stimulation (tDCS) stimulation, the susceptibility to motion sickness was reduced, as reflected by the significant increase in off-vertical axis rotation (OVAR) duration required to induce moderate nausea. Also, we observe a significant reduction in the time taken for symptom recovery. In contrast, following left anodal stimulation, we did not observe any significant effects (right upper panel). (B) Adult motion sickness susceptibility scores (MSB) showed significant correlation with the change in OVAR duration (post-pre tDCS) for the left cathodal stimulation only (left lower panel), indicating that less susceptible subjects derived the largest benefit from tDCS. Error bars represent standard errors. ${ }^{*} p<0.05 ; * p<0.01$.

was significantly increased $(t=2.68, p<0.05$; figure, A). In contrast, for anodal stimulation, the measurement $\times$ condition interaction was not significant. That is, following left cathodal stimulation, it took subjects in the second OVAR session 207 seconds (range 32-382 seconds) longer to develop moderate nausea, whereas following left anodal stimulation subjects developed moderate nausea on average 57 seconds sooner (range 22 to -153 seconds). Notably, those subjects less susceptible to motion sickness (i.e., lower MSB scores) derived the largest benefit following left cathodal tDCS stimulation $(r=0.86, p<0.001$; figure, B). Further, the time taken to recover following cathodal stimulation was significantly reduced ( $t=6.0, p<0.001$; figure, A).
Discussion. Following cathodal tDCS over the left hemisphere, we observed both an increased duration in the time taken to develop moderate nausea during OVAR and a more rapid recovery from symptoms. As no significant effects were observed during anodal stimulation, this excludes the role of both adaptation and nonspecific effects due to tDCS. ${ }^{10}$ We provide a novel treatment for motion sickness that is, so far, apparently free of side effects.

*Q. Arshad and N. Cerchiai contributed equally to this work. From Imperial College (Q.A., N.C., U.G., Y.N., R.E.R., M.A.G., A.M.B.), Charing Cross Hospital, London, UK; Otorinolaringoiatria 1 Universitaria (N.C., A.P.C.), Pisa, Italy; and the University of Westminster (J.F.G.), London, UK.

Author contributions: Q. Arshad: conceptualized study, acquired data, and wrote the manuscript. N. Cerchiai: conceptualized study and acquired data. U. Goga: acquired data and revised 
manuscript. Y. Nigmatullina: data analysis and figure preparation. E. Roberts: data analysis and revised manuscript. A. Casani: revised manuscript. J. Golding: conceptualized study, technical expertise, and revised manuscript. M. Gresty: conceptualized study, technical expertise, and wrote manuscript. A Bronstein: conceptualized study, supervised study, and wrote manuscript.

Study funding: No targeted funding reported.

Disclosure: The authors report no disclosures relevant to the manuscript. Go to Neurology.org for full disclosures. The Article Processing Charge was paid by Research Councils-UK (RCUK).

This is an open access article distributed under the terms of the Creative Commons Attribution License 4.0 (CC BY), which permits unrestricted use, distribution, and reproduction in any medium, provided the original work is properly cited.

Received September 24, 2014. Accepted in final form April 14, 2015. Correspondence to Dr. Bronstein: a.bronstein@imperial.ac.uk

(C) 2015 American Academy of Neurology

1. Murdin L, Chamberlain F, Cheema S, et al. Motion sickness in migraine and vestibular disorders. J Neurol Neurosurg Psychiatry 2015;86:585-587.

2. Turner M, Griffin MJ. Motion sickness in public road transport: the effect of driver, route and vehicle. Ergonomics 1999; 42:1646-1664.
3. Turner M, Griffin MJ, Holland I. Airsickness and aircraft motion during short-haul flights. Aviat Space Environ Med 2000;71:1181-1189.

4. Lawther A, Griffin MJ. A survey of the occurrence of motion sickness amongst passengers at sea. Aviat Space Environ Med 1988;59:399-406.

5. Golding JF, Gresty MA. Pathophysiology and treatment of motion sickness. Curr Opin Neurol 2015;28:83-88.

6. Arshad Q, Nigmatullina Y, Roberts RE, Bhrugubanda V, Asavarut P, Bronstein AM. Left cathodal trans-cranial direct current stimulation of the parietal cortex leads to an asymmetrical modulation of the vestibular-ocular reflex. Brain Stimul 2014;7:85-91.

7. Bijveld M, Bronstein AM, Golding JF, Gresty MA. Nauseogenicity of off-vertical axis rotation vs. equivalent visual motion. Aviat Space Environ Med 2008;79:661-665.

8. Golding JF. Motion sickness susceptibility questionnaire revised and its relationship to other forms of sickness. Brain Res Bull 1998;47:507-516.

9. Golding JF, Stott JR. Objective and subjective time courses of recovery from motion sickness assessed by repeated motion challenges. J Vestib Res 1997;7:421-428.

10. Kyriakareli A, Cousins S, Pettorossi VE, Bronstein AM. Effect of transcranial direct current stimulation on vestibular-ocular and vestibulo-perceptual thresholds. Neuroreport 2013;24:808-812.
Marisela E. Dy, MD

Katherine B. Sims, MD

Jennifer Friedman, MD

Supplemental data at Neurology.org
TPP1 DEFICIENCY: RARE CAUSE OF ISOLATED CHILDHOOD-ONSET PROGRESSIVE ATAXIA

Neuronal ceroid lipofuscinoses (NCLs) are neurodegenerative disorders characterized by lysosomal ceroid deposition. Historically, NCLs were classified by onset age and electron microscopy abnormalities as infantile, late infantile, juvenile, and adult. ${ }^{1,2}$ Molecular techniques have broadened diagnostic subgroups with identification of at least 13 NCL genes (http:// www.ucl.ac.uk/ncl/mutation), though categorization remains difficult due to wide-ranging genetic, allelic, and phenotypic heterogeneity. ${ }^{1,2}$

CLN2 disease (late infantile NCL) is an autosomal recessive disorder associated with deficiency of tripeptidyl-peptidase-1 (TPP1). ${ }^{1-3} \quad$ Neurodevelopmental regression typically begins between 2 and 4 years of age with onset of seizures, cognitive decline, ataxia, visual loss, spasticity, and death usually in the 2nd decade. ${ }^{1-3}$ Tissue electron microscopic studies typically reveal curvilinear profiles. ${ }^{1,2}$ A recent report of 6 adult members in 2 families, with symptom onset in childhood, broadened the phenotype of TPP1 partial deficiency to include spinocerebellar ataxia (SCAR7). ${ }^{4,5}$ All patients were compound heterozygotes (c.509-1G $>$ C/c.1397T $>\mathrm{G}$ ). ${ }^{4,5}$ We report a child with progressive ataxia and compound heterozygous TPP1 mutations (common splice, c.509$1 \mathrm{G}>\mathrm{C}$ and c.1029G $>$ C, p. Glu343Asp) associated with TPP1 enzyme deficiency. This case highlights the power of next-generation sequencing (NGS) in diagnosing rare and atypical disease. Increased awareness of TPP1-deficiency ataxia phenotype is crucial to identify patients with atypical CLN2 disease. These patients may benefit from TPP1 enzyme replacement therapy currently in trials for classic lateinfantile CLN2 disease.

Case report. The patient is a 10 -year-old African American/Caucasian girl with prenatal gastroschisis. Delivery was by cesarean section at 35 weeks. Development was normal except for stuttering (age 3). Fine motor difficulties began at age 4. Abnormalities of gait, balance, coordination, and difficulties with academic performance were noted at age 6 . Neurocognitive assessment (age 8) identified impaired visual processing, visual memory, and attention, and expressive/receptive language skills in the below average to average range. There has been no frank loss of cognitive skills, although symptoms of cerebellar dysfunction have been progressive. The patient continues to ambulate and run independently with balance difficulties, but can no longer ride a bike.

Neurologic examination is notable for scanning speech. Ophthalmologic examination demonstrates unilateral Mittendorf dot, intermittent bilateral horizontal gaze-evoked nystagmus, saccadic breakdown of ocular pursuit, overshoot of horizontal saccades, and oculomotor apraxia. Movement abnormalities include bilateral upper extremity dysmetria, slowed fine finger movements, and truncal titubation. Gait is wide-based and moderately unsteady. The patient is able to stand on one foot 


\title{
Neurology
}

\author{
Electrocortical therapy for motion sickness \\ Qadeer Arshad, Niccolo Cerchiai, Usman Goga, et al. \\ Neurology 2015;85;1257-1259 Published Online before print September 4, 2015 \\ DOI 10.1212/WNL.0000000000001989
}

This information is current as of September 4, 2015

Updated Information \& Services

References

Subspecialty Collections

Permissions \& Licensing

Reprints including high resolution figures, can be found at: http://n.neurology.org/content/85/14/1257.full

This article cites 10 articles, 1 of which you can access for free at: http://n.neurology.org/content/85/14/1257.full\#ref-list-1

This article, along with others on similar topics, appears in the following collection(s):

All Neurotology

http://n.neurology.org/cgi/collection/all_neurotology

Information about reproducing this article in parts (figures,tables) or in its entirety can be found online at:

http://www.neurology.org/about/about_the_journal\#permissions

Information about ordering reprints can be found online:

http://n.neurology.org/subscribers/advertise

Neurology ${ }^{\circledR}$ is the official journal of the American Academy of Neurology. Published continuously since 1951, it is now a weekly with 48 issues per year. Copyright (C 2015 American Academy of Neurology. All rights reserved. Print ISSN: 0028-3878. Online ISSN: 1526-632X.

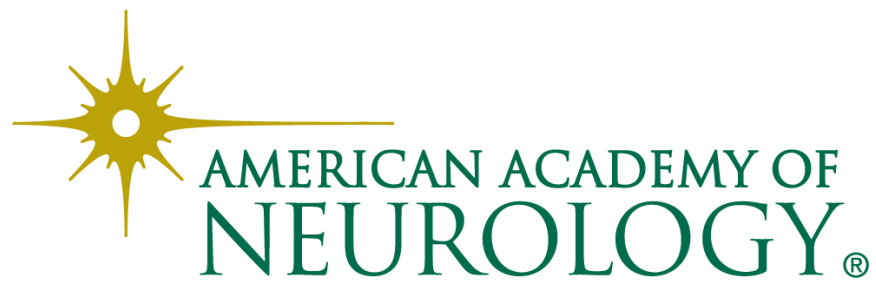

